\title{
Metformin Pharmacogenetics: Effects of SLC22A1, SLC22A2, and SLC22A3 Polymorphisms on Glycemic Control and HbA1c Levels
}

\author{
Laith N. AL-Eitan 1,2,*(D), Basima A. Almomani ${ }^{3} \mathbb{D}^{\mathbb{D}}$, Ahmad M. Nassar ${ }^{4}$, Barakat Z. Elsaqa ${ }^{5}$ \\ and Nesreen A. Saadeh 6 \\ 1 Department of Applied Biological Sciences, Jordan University of Science and Technology, \\ Irbid 22110, Jordan \\ 2 Department of Biotechnology and Genetic Engineering, Jordan University of Science and Technology, \\ Irbid 22110, Jordan \\ 3 Department of Clinical Pharmacy, Jordan University of Science and Technology, Irbid 22110, Jordan; \\ baalmomani1@just.edu.jo \\ 4 Department of Internal Medicine, MedStar Washington Hospital Center, Georgetown University, \\ Washington, DC 20010, USA; ahmadnassar.md@gmail.com \\ 5 Faculty of Medicine, Jordan University of Science and Technology, Irbid 22110, Jordan; \\ barakat.saqa@gmail.com \\ 6 Department of Internal Medicine, Jordan University of Science and Technology, Irbid 22110, Jordan; \\ nasaadeh@just.edu.jo \\ * Correspondence: lneitan@just.edu.jo; Tel.: +962-2-7201000 (ext. 23464); Fax: +962-2-7201071
}

Received: 4 January 2019; Accepted: 20 March 2019; Published: 25 March 2019

\begin{abstract}
Type 2 diabetes mellitus (T2DM) constitutes a major portion of Jordan's disease burden, and incidence rates are rising at a rapid rate. Due to variability in the drug's response between ethnic groups, it is imperative that the pharmacogenetics of metformin be investigated in the Jordanian population. The objective of this study was to investigate the relationship between twenty-one single nucleotide polymorphisms (SNPs) in the SLC22A1, SLC22A2, and SLC22A3 genes and their effects on metformin pharmacogenetics in Jordanian patients diagnosed with type 2 diabetes mellitus. Blood samples were collected from 212 Jordanian diabetics who fulfilled the inclusion criteria, which were then used in SNP genotyping and determination of HbA1c levels. The rs12194182 SNP in the SLC22A3 gene was found to have a significant association $(p<0.05)$ with lower mean $\mathrm{HbA} 1 \mathrm{c}$ levels, and this association more pronounced in patients with the CC genotype (i.e., $p$-value was significant before correcting for multiple testing). Moreover, the multinomial logistic regression analysis showed that SNP genotypes within the SLC22A1, SLC22A2, and SLC22A3 genes, body mass index (BMI) and age of diagnosis were significantly associated with glycemic control $(p<0.05)$. The results of this study can be used to predict response to metformin and other classes of T2DM drugs, making treatment more individualized and resulting in better clinical outcomes.
\end{abstract}

Keywords: metformin; pharmacogenetics; solute carrier gene; SNPs; HbA1c; glycemic control

\section{Introduction}

Diabetes mellitus (DM) refers to a heterogenous group of chronic metabolic disorders that affects the body's ability to regulate blood glucose levels [1]. Although better understanding of the disease is creating newer classifications, DM can be broadly subdivided into type 1 DM (T1DM), where autoimmune processes cause absolute insulin deficiency, and type 2 DM (T2DM), in which a mixture of genetic and environmental factors leads to impaired insulin production [2]. By far, T2DM is 
the most common manifestation of the disease, accounting for up to $90 \%$ of global diabetic cases [3]. In the Arab world, the number of T2DM cases is predicted to undergo a $96.2 \%$ increase by 2035 , and Jordan, with a T2DM prevalence of $17.4 \%$ as of 2008 , is no exception [4,5]. Risk factors for T2DM are particularly rampant among the Jordanian population as a result of a high prevalence of metabolic syndrome, physical inactivity, obesity, cigarette smoking, and poor dietary habits [6-10].

The first line of treatment for T2DM is metformin, a medication that is favored for its relative lack of side effects and its excellent patient tolerance [11]. However, due to differences in individual genetic profiles, metformin does not perform equally nor optimally in all patients, leading to a reduction in the drug's efficacy and safety [12]. Further compounding this issue is the fact that, in a study including 237 Jordanians with T2DM, more than half were observed to have poor levels of glycemic control despite metformin being a part of the majority of treatment plans [13]. As a result, discerning the genetic component underlying the variation in metformin response is necessary, especially in populations with a high prevalence of T2DM [14]. In Jordan, different clinical characteristics of diabetes have been reported between the genetically distinct Arab, Chechen, and Circassian communities, warranting different DM management and treatment protocols for each [15].

Metformin functions by reducing hepatic glucose production while simultaneously increasing peripheral glucose uptake [16]. Metformin is unique in that it does not need to undergo metabolic breakdown to affect control of blood glucose levels [17]. In order for it to decrease hepatic glucose production, however, metformin requires membrane transport proteins encoded for by solute carrier (SLC) genes in order to enter the cells [18]. The solute carrier family 22 member 1 (SLC22A1) and 3 (SLC22A3) genes encode the OCT1 and OCT3 proteins, respectively, which are largely responsible for hepatic and intestinal metformin uptake [19]. In addition, OCT2 (SLC22A2) is the main facilitator of metformin uptake by renal epithelial cells [20]. Various single nucleotide polymorphisms (SNPs) in the SLC22A1, SLC22A2, and SLC22A3 genes have been found to influence metformin pharmacodynamics and pharmacokinetics, which, in turn, affect patient response to the drug [21].

Despite comprising a substantial proportion of Jordan's disease burden, T2DM has been the subject of virtually no studies with regard to its genetic component and the effect of the latter on metformin response. Therefore, the aim of the present study is to address this gap in the literature by investigating the association between certain SLC22A1, SLC22A2, and SLC22A3 SNPs and metformin effectiveness, as determined by levels of glycemic control and glycohemoglobin (HbA1c), in Jordanian T2DM patients.

\section{Materials and Methods}

\subsection{Patient Recruitment}

A total of 300 subjects were approached at the Diabetes Clinic of King Abdullah University Hospital (KAUH), a tertiary referral hospital located in the north of Jordan and the primary teaching hospital for Jordan University of Science and Technology (JUST). All enrolled subjects were Jordanians previously diagnosed with diabetes who were at the Diabetes Clinic for follow-up and assessment. Subjects included in the study had an established diagnosis of T2DM according to the diagnostic guidelines set by the World Health Organization (WHO) and the American Diabetes Association (ADA). Additional inclusion criteria comprised the patients having been diabetic for at least six months prior to data collection, having regular and compliant intake of metformin as the primary pharmacologic agent in their treatment plan, and being over the age of 18. A total of 88 subjects who were not taking metformin and subjects with a failed genetic analysis (Table 1) were excluded. 
Table 1. List of studied SNPs, chromosomal positions, gene locations based on the National Center for Biotechnology Information (NCBI) Human Genome Assembly Build 36.3 and diabetes mellitus (DM) patients fail to genotype.

\begin{tabular}{|c|c|c|c|c|c|}
\hline Gene & SNP ID & Chromosomal Position & SNP & Gene Location & DM Patients Fail to Genotype \\
\hline \multirow{7}{*}{ OCT1 } & rs1867351 & $6: 160543123$ & $\mathrm{~T}>\mathrm{C}$ & Exon 1 & 2 \\
\hline & rs2282143 & $6: 160557643$ & $\mathrm{C}>\mathrm{T}$ & Exon 3 & 0 \\
\hline & rs2297374 & 6:160551204 & $\mathrm{C}>\mathrm{T}$ & Intron 9 & 1 \\
\hline & rs461473 & $6: 160543562$ & $\mathrm{G}>\mathrm{A}$ & Intron 1 & 0 \\
\hline & rs4646272 & 6:160551093 & $\mathrm{T}>\mathrm{G}$ & Intron 1 & 1 \\
\hline & rs622342 & 6:160572866 & $\mathrm{A}>\mathrm{C}$ & Intron 9 & 55 \\
\hline & rs683369 & 6:160551204 & $C>G$ & Exon 2 & 0 \\
\hline \multirow{10}{*}{ OCT2 } & rs10755577 & 6:160219462 & $\mathrm{C}>\mathrm{T}$ & Intron 10 & 1 \\
\hline & rs17588242 & 6:160242199 & $\mathrm{C}>\mathrm{T}$ & Intron 8 & 8 \\
\hline & rs17589858 & $6: 160268084$ & $\mathrm{G}>\mathrm{A}$ & Promoter & 9 \\
\hline & rs2928035 & $6: 160560871$ & $\mathrm{~A} / \mathrm{G}$ & Intron 10 & 16 \\
\hline & rs3127573 & 6:160681393 & $\mathrm{A} / \mathrm{G}$ & Promoter & 47 \\
\hline & rs316024 & 6:160682236 & $A>G$ & Promoter & 0 \\
\hline & rs316025 & 6:160603371 & $\mathrm{C}>\mathrm{T}$ & Promoter & 1 \\
\hline & rs316026 & 6:160604360 & $\mathrm{T} / \mathrm{C}$ & Promoter & 1 \\
\hline & rs533452 & $6: 160276730$ & $\mathrm{C}>\mathrm{T}$ & Promoter & 20 \\
\hline & rs662301 & 6:160696919 & $\mathrm{C}>\mathrm{T}$ & Promoter & 0 \\
\hline \multirow{4}{*}{ OCT3 } & rs12194182 & 6:160834515 & $\mathrm{C} / \mathrm{T}$ & Intron 5 & 15 \\
\hline & rs2292334 & 6:160858188 & $\mathrm{G}>\mathrm{A}$ & Exon 7 & 3 \\
\hline & rs2504927 & $6: 160780420$ & $\mathrm{G}>\mathrm{A}$ & Intron 7 & 18 \\
\hline & rs3123634 & 6:160381207 & $\mathrm{C}>\mathrm{T}$ & Intron 1 & 3 \\
\hline
\end{tabular}

\subsection{Study Design}

A comparison between T2DM patients taking metformin and different SLC22A1, SLC22A2, and SLC22A3 SNP genotypes was conducted to evaluate the effect of these genotypes on certain clinical outcomes (glycemic control and Hba1c levels). The selection process for the different SNPs was based on previous reports of their clinical and functional relevance in the field of metformin pharmacogenetics. Ethical approval to conduct the study was granted by the Ethics Committee of JUST. All procedures employed in this study were in accordance with the Declaration of Helsinki (1964). Written informed consent was obtained from all enrolled subjects after being given details of the study's purpose and assurance of patient confidentiality.

\subsection{Data Collection}

Data collection took place between 2014 and 2015 at the Diabetes Clinic at KAUH by means of direct interviews. Clinical data was collected using a questionnaire designed for the study and filled out by healthcare personnel interviewing the subjects. Obtained clinical data included demographic details, age at diagnosis of DM, duration of DM, comorbidities, and medication history (data not shown). Blood samples for determination of $\mathrm{HbA1c}$ levels and DNA extraction were obtained during the interview by a phlebotomist using ethylenediamine tetraacetic acid (EDTA) collection tubes. HbA1c serum levels were measured at KAUH using standard laboratory techniques.

\subsection{Definition of Variables}

As per the ADA's 2016 guidelines, adequate glycemic control was defined as an Hba1c level of less than $7.0 \%$, while poor glycemic control was defined as an Hba1c level of greater than or equal to $7.0 \%$.

\subsection{SNP Genotyping}

Genomic DNA was extracted from whole blood using a Promega kit (Promega Corporation, Madison, WI, USA). All individuals were genotyped for the twenty-one chosen SNPs listed in Table 1. Genotyping took place in Australia using the Sequenom MassARRAY system (iPLEX GOLD) 
(Sequenom, San Diego, CA, USA), and the manufacturer's instructions were meticulously followed. Briefly, PCR was performed to amplify target regions, followed by treatment with shrimp alkaline phosphatase for dephosphorylation of unicorporated dNTPs. Then, the iPLEX extension reaction, which involves a single nucleotide extension of SNP sites, was carried out. Finally, matrix-assisted laser desorption/ionization-time of flight (MALDI-TOF) mass spectrometric analysis was carried out in order to detect differences in mass. The primers for the PCR and iPLEX extension reaction were designed using the Assay Design Suite. MassARRAY Workstation (v. 3.3) (Sequenom, San Diego, CA, USA) was used to process the iPLEX SpectroCHIP Bioarray (Sequenom), and Typer Analyzed (v. 4.0.2) (Sequenom) was used to analyze the genotypes obtained from the assays.

\subsection{Statistical Analysis}

Testing for consistency with the Hardy-Weinberg equilibrium was carried out using PowerMarker software (v. 3.25). Statistical analysis was performed using the Statistical Package for Social Sciences (SPSS) software (v. 22). Continuous data was presented as means \pm standard deviation (SD) and categorical data was presented in numerical form. Variables were compared using Pearson's chi-squared test, $t$-test, and ANOVA F-test as appropriate. Multinomial logistic regression analysis was applied to further test the association of SNP with glycemic control after adjusting for age, BMI and age of diabetes diagnosis as covariates. A $p$-value cutoff of $<0.05$ was used as a determinant of statistical significance.

\section{Results}

\subsection{Patient Characteristics}

A total of 300 diabetics were initially approached, and 212 patients were enrolled in the study after fulfilling the inclusion criteria. As can be seen from Table 2, the mean age of the studied sample was $56.64 \pm 9.4$ years. The mean Hba1c level was $7.93 \pm 2.1 \%$, and more than half $(59.9 \%)$ of the studied subjects had inadequate glycemic control. No statistically significant difference was found between male and female subjects.

Table 2. Clinical characteristics of Jordanian patients with diabetes.

\begin{tabular}{|c|c|c|c|c|}
\hline Category & Subcategory & $\begin{array}{c}\text { Adequate } \\
\text { Glycemic Control }\end{array}$ & $\begin{array}{c}\text { Inadequate } \\
\text { Glycemic Control }^{b}\end{array}$ & $p$-Value ${ }^{\text {a }}$ \\
\hline \multirow[b]{2}{*}{ Gender } & Male & $30(14.2 \%)$ & $52(24.5 \%)$ & \multirow[b]{2}{*}{0.472} \\
\hline & Female & $55(25.9 \%)$ & $75(35.4 \%)$ & \\
\hline Age & & $57.17 \pm 9.7$ & $56.30 \pm 9.3$ & 0.504 \\
\hline $\mathrm{BMI}^{\mathrm{c}}\left(\mathrm{kg} / \mathrm{m}^{2}\right)$ & & $31.18 \pm 5.1$ & $33.16 \pm 6.4$ & 0.023 \\
\hline $\begin{array}{l}\text { Age of diabetes } \\
\text { diagnosis }\end{array}$ & & $49.46 \pm 9.2$ & $46.74 \pm 9.6$ & 0.042 \\
\hline \multirow{8}{*}{$\begin{array}{l}\text { Glycemic } \\
\text { Parameters }\end{array}$} & Fasting glucose & $6.55 \pm 1.8$ & $9.44 \pm 4.5$ & $7.3 \times 10^{-8}$ \\
\hline & $\mathrm{HbA} 1 c^{\mathrm{d}}$ & $6.27 \pm 1.3$ & $9.08 \pm 1.8$ & $5 \times 10^{-26}$ \\
\hline & HDL e $^{\mathrm{e}}$ cholesterol (mmol/L) & $1.21 \pm 0.3$ & $1.10 \pm 0.3$ & 0.010 \\
\hline & $\mathrm{LDL}^{\mathrm{f}}$ cholesterol $(\mathrm{mmol} / \mathrm{L})$ & $2.80 \pm 0.9$ & $3.03 \pm 0.8$ & 0.024 \\
\hline & Cholesterol (mmol/L) & $4.30 \pm 1.0$ & $4.50 \pm 1.1$ & 0.178 \\
\hline & Triglycerides (mmol/L) & $1.69 \pm 1.2$ & $2.10 \pm 1.7$ & 0.530 \\
\hline & Serum creatinine $(\mu \mathrm{mol} / \mathrm{L})$ & $74.14 \pm 24.3$ & $75.92 \pm 25.7$ & 0.613 \\
\hline & $\begin{array}{l}\text { Creatinine clearance } \\
(\mathrm{mL} / \mathrm{min})\end{array}$ & $109.82 \pm 35.0$ & $118.80 \pm 42.0$ & 0.105 \\
\hline
\end{tabular}

${ }^{a} p$-value $<0.05$ is considered significant, ${ }^{b}$ defined as $\mathrm{HbA} 1 \mathrm{c}$ level $\geq 7.0 \%$ according to the American diabetic association (ADA) guidelines, ${ }^{c}$ BMI: Body mass index, ${ }^{d}$ HbA1c: glycated haemoglobin, ${ }^{e}$ HDL: High-density lipoprotein, ${ }^{\mathrm{f}}$ LDL: Low-density lipoprotein. 
3.2. Minor Allelic Frequency of the Investigated OCT Candidate Gene SNPs and Their Associations with DM Treatment Response

Three OCT genes essential to drug metabolism were included in this study. Table 3 shows the investigated candidate SNPs within these genes and the allelic distribution frequency for each gene's minor allele as well as the Hardy Weinberg equilibrium (HWE) $p$-value. All estimated SNP genotypes were in HWE and normally distributed with $p$-value $>0.05$ except two SNPs (rs622342 and rs2928035) within SLC22A1 gene. The present study did not find a significant association of glycemic control in T2DM patients taking metformin with seven SNPs (rs1867351, rs2282143, rs2282143, rs461473, rs4646272, rs622342, rs683369) in the SLC22A1 gene and 10 SNPs (rs10755577, rs17588242, rs17589858, rs2928035, rs3127573, rs316024, rs316025, rs316026, rs533452, rs662301) in the SLC22A2 gene (Tables 4 and 5). Additionally, it was found that the rs12194182 SNP in the SLC22A3 gene is associated with lower mean $\mathrm{HbA} 1 \mathrm{c}$ levels in T2DM patients ( $p$-value $<0.05$, i.e., $p$-value was significant before correcting for multiple testing). Conversely, this SNP showed no association with adequacy or inadequacy of glycemic control as presented in Table 6. The other studied SNPs (rs2292334, rs2504927, and rs3123634) within SLC22A3 gene exhibited no significant association with glycemic control in T2DM patients taking metformin.

Table 3. Minor allele frequencies among DM patients and the HWE $p$-value of candidate polymorphisms in OCT1, OCT2 and OCT3 genes.

\begin{tabular}{|c|c|c|c|c|c|}
\hline Gene & SNP ID & $\mathrm{MA}^{\mathrm{a}}$ & MAF ${ }^{b}$ & $x^{2}$ & HWE $^{c} p$-Value \\
\hline \multirow{7}{*}{ OCT1 } & rs1867351 & $\mathrm{G}$ & 0.19 & 0.04 & 0.85 \\
\hline & rs2282143 & $\mathrm{T}$ & 0.02 & 0.06 & 0.81 \\
\hline & rs2297374 & $\mathrm{C}$ & 0.46 & 0.07 & 0.79 \\
\hline & rs461473 & A & 0.10 & 0.60 & 0.44 \\
\hline & rs4646272 & G & 0.04 & 1.40 & 0.24 \\
\hline & rs622342 & $\mathrm{C}$ & 0.23 & 4.03 & 0.04 \\
\hline & rs683369 & G & 0.13 & 0.79 & 0.37 \\
\hline \multirow{10}{*}{ OCT2 } & rs10755577 & $\mathrm{T}$ & 0.18 & 0.29 & 0.59 \\
\hline & rs17588242 & $\mathrm{C}$ & 0.25 & 0.01 & 0.92 \\
\hline & rs17589858 & G & 0.25 & 0.01 & 0.94 \\
\hline & rs2928035 & $\mathrm{G}$ & 0.19 & 4.96 & 0.03 \\
\hline & rs3127573 & $\mathrm{C}$ & 0.08 & 0.04 & 0.85 \\
\hline & rs316024 & $\mathrm{A}$ & 0.21 & 3.69 & 0.06 \\
\hline & rs316025 & A & 0.24 & 2.50 & 0.11 \\
\hline & rs316026 & $\mathrm{T}$ & 0.42 & 2.38 & 0.12 \\
\hline & rs533452 & $\mathrm{T}$ & 0.29 & 0.05 & 0.82 \\
\hline & rs662301 & $\mathrm{T}$ & 0.05 & 0.25 & 0.61 \\
\hline \multirow{4}{*}{ ОСТЗ } & rs12194182 & $\mathrm{C}$ & 0.09 & 1.12 & 0.29 \\
\hline & rs2292334 & $\mathrm{T}$ & 0.28 & 1.02 & 0.32 \\
\hline & rs2504927 & G & 0.48 & 1.26 & 0.26 \\
\hline & rs3123634 & $\mathrm{T}$ & 0.37 & 2.28 & 0.13 \\
\hline
\end{tabular}

${ }^{a}$ MA: minor allele. ${ }^{b}$ MAF: minor allele frequency. ${ }^{c}$ HWE: Hardy-Weinberg equilibrium. 
Table 4. Effect of genotype distribution of studied SNPs for OCT1 gene on glycemic control and on $\mathrm{HbA} 1 \mathrm{c}$ level in Jordanian T2DM patients receiving metformin.

\begin{tabular}{|c|c|c|c|c|c|c|c|c|}
\hline Gene & SNP ID & Genotype & Total & $\begin{array}{l}\text { Adequate } \\
\text { Glycemic } \\
\text { Control }\end{array}$ & $\begin{array}{l}\text { Inadequate } \\
\text { Glycemic } \\
\text { Control }\end{array}$ & $p$-Value * & $\begin{array}{l}\text { Mean HbA1c } \\
\quad \pm \text { SD }\end{array}$ & $p$-Value * \\
\hline \multirow{21}{*}{ OCT1 } & \multirow{3}{*}{ rs1867351 } & $\mathrm{AA}$ & 138 & 58 & 80 & \multirow{3}{*}{0.187} & $7.93 \pm 2.06$ & \multirow{3}{*}{0.136} \\
\hline & & GA & 65 & 21 & 44 & & $8.21 \pm 2.04$ & \\
\hline & & GG & 7 & 5 & 2 & & $6.45 \pm 2.33$ & \\
\hline & \multirow{3}{*}{ rs2282143 } & $\mathrm{CC}$ & 205 & 84 & 121 & \multirow{3}{*}{0.153} & $7.98 \pm 2.11$ & \multirow{3}{*}{0.872} \\
\hline & & $\mathrm{CT}$ & 7 & 1 & 6 & & $8.11 \pm 1.48$ & \\
\hline & & TT & 0 & 0 & 0 & & - & \\
\hline & \multirow{3}{*}{ rs2297374 } & $\mathrm{CC}$ & 46 & 21 & 25 & \multirow{3}{*}{0.285} & $7.76 \pm 1.80$ & \multirow{3}{*}{0.180} \\
\hline & & $\mathrm{TC}$ & 103 & 43 & 60 & & $7.83 \pm 2.02$ & \\
\hline & & $\mathrm{TT}$ & 62 & 20 & 42 & & $8.43 \pm 2.36$ & \\
\hline & \multirow{3}{*}{ rs461473 } & AA & 1 & 1 & 0 & \multirow{3}{*}{0.311} & 5.60 & \multirow{3}{*}{0.253} \\
\hline & & GA & 39 & 13 & 26 & & $8.36 \pm 2.07$ & \\
\hline & & GG & 172 & 71 & 101 & & $7.91 \pm 2.09$ & \\
\hline & \multirow{3}{*}{ rs4646272 } & GG & 1 & 0 & 1 & \multirow{3}{*}{0.074} & 10.90 & \multirow{3}{*}{0.277} \\
\hline & & GT & 15 & 2 & 13 & & $8.48 \pm 2.28$ & \\
\hline & & TT & 195 & 82 & 113 & & $7.94 \pm 2.07$ & \\
\hline & \multirow{3}{*}{ rs622342 } & AA & 88 & 33 & 55 & \multirow{3}{*}{0.432} & $8.14 \pm 2.20$ & \multirow{3}{*}{0.277} \\
\hline & & $\mathrm{CA}$ & 65 & 24 & 41 & & $8.16 \pm 2.17$ & \\
\hline & & $\mathrm{CC}$ & 4 & 1 & 3 & & $8.10 \pm 2.09$ & \\
\hline & \multirow{3}{*}{ rs683369 } & $\mathrm{CC}$ & 160 & 66 & 94 & \multirow{3}{*}{0.146} & $7.83 \pm 1.89$ & \multirow{3}{*}{0.072} \\
\hline & & GC & 50 & 17 & 33 & & $8.52 \pm 2.61$ & \\
\hline & & GG & 2 & 2 & 0 & & $6.45 \pm 0.48$ & \\
\hline
\end{tabular}

Table 5. Effect of genotype distribution of studied SNPs for OCT2 gene on glycemic control and on $\mathrm{HbA} 1 \mathrm{c}$ level in Jordanian T2DM patients receiving metformin.

\begin{tabular}{|c|c|c|c|c|c|c|c|c|}
\hline Gene & SNP ID & Genotype & Total & $\begin{array}{c}\text { Adequate } \\
\text { Glycemic } \\
\text { Control }\end{array}$ & $\begin{array}{c}\text { Inadequate } \\
\text { Glycemic } \\
\text { Control }\end{array}$ & $p$-Value * & $\begin{array}{c}\text { Mean HbA1c } \\
\quad \pm \text { SD }\end{array}$ & $p$-Value * \\
\hline \multirow{30}{*}{ OCT2 } & \multirow{3}{*}{ rs10755577 } & $\mathrm{TT}$ & 8 & 5 & 3 & \multirow{3}{*}{0.222} & $7.16 \pm 1.13$ & \multirow{3}{*}{0.490} \\
\hline & & $\mathrm{TC}$ & 60 & 40 & 20 & & $8.20 \pm 2.17$ & \\
\hline & & $\mathrm{CC}$ & 143 & 84 & 59 & & $7.94 \pm 2.10$ & \\
\hline & \multirow{3}{*}{ rs17588242 } & $\mathrm{CC}$ & 13 & 7 & 6 & \multirow{3}{*}{0.105} & $7.91 \pm 2.16$ & \multirow{3}{*}{0.221} \\
\hline & & CT & 78 & 32 & 46 & & $8.14 \pm 2.21$ & \\
\hline & & $\mathrm{TT}$ & 113 & 40 & 73 & & $7.98 \pm 2.09$ & \\
\hline & \multirow{3}{*}{ rs17589858 } & $\mathrm{CC}$ & 114 & 48 & 66 & \multirow{3}{*}{0.772} & $7.94 \pm 2.04$ & \multirow{3}{*}{0.628} \\
\hline & & CG & 76 & 27 & 49 & & $8.08 \pm 2.13$ & \\
\hline & & GG & 13 & 6 & 7 & & $8.31 \pm 2.14$ & \\
\hline & \multirow{3}{*}{ rs2928035 } & $\mathrm{AA}$ & 133 & 47 & 86 & \multirow{3}{*}{0.152} & $8.08 \pm 2.09$ & \multirow{3}{*}{0.237} \\
\hline & & AG & 51 & 22 & 29 & & $8.07 \pm 2.03$ & \\
\hline & & GG & 12 & 6 & 60 & & $7.98 \pm 2.09$ & \\
\hline & \multirow{3}{*}{ rs3127573 } & $\mathrm{CC}$ & 1 & 1 & 0 & \multirow{3}{*}{0.552} & 6.30 & \multirow{3}{*}{0.502} \\
\hline & & $\mathrm{CT}$ & 26 & 12 & 14 & & $7.60 \pm 1.72$ & \\
\hline & & $\mathrm{TT}$ & 138 & 71 & 112 & & $8.03 \pm 2.13$ & \\
\hline & \multirow{3}{*}{ rs316024 } & AA & 21 & 10 & 11 & \multirow{3}{*}{0.455} & $7.93 \pm 2.50$ & \multirow{3}{*}{0.349} \\
\hline & & AG & 73 & 32 & 41 & & $7.71 \pm 1.94$ & \\
\hline & & GG & 118 & 43 & 75 & & $7.98 \pm 2.09$ & \\
\hline & \multirow{3}{*}{ rs316025 } & $\mathrm{AA}$ & 16 & 7 & 9 & \multirow{3}{*}{0.641} & $8.12 \pm 2.52$ & \multirow{3}{*}{0.798} \\
\hline & & GA & 68 & 26 & 42 & & $7.84 \pm 1.93$ & \\
\hline & & GG & 127 & 51 & 76 & & $7.98 \pm 2.09$ & \\
\hline & \multirow{3}{*}{ rs316026 } & $\mathrm{CC}$ & 76 & 28 & 48 & \multirow{3}{*}{0.694} & $8.16 \pm 2.07$ & \multirow{3}{*}{0.559} \\
\hline & & $\mathrm{CT}$ & 92 & 40 & 52 & & $7.77 \pm 2.07$ & \\
\hline & & $\mathrm{TT}$ & 43 & 17 & 26 & & $7.98 \pm 2.09$ & \\
\hline & \multirow{3}{*}{ rs533452 } & $\mathrm{CC}$ & 97 & 38 & 59 & \multirow{3}{*}{0.797} & $8.17 \pm 2.10$ & \multirow{3}{*}{0.308} \\
\hline & & $\mathrm{TC}$ & 78 & 31 & 47 & & $7.84 \pm 2.05$ & \\
\hline & & TT & 17 & 6 & 11 & & $8.25 \pm 2.33$ & \\
\hline & \multirow{3}{*}{ rs662301 } & $\mathrm{CC}$ & 190 & 77 & 113 & & $7.97 \pm 2.09$ & \\
\hline & & $\mathrm{CT}$ & 21 & 7 & 14 & 0.385 & $8.15 \pm 2.16$ & 0.677 \\
\hline & & $\mathrm{TT}$ & 1 & 1 & 0 & & 6.30 & \\
\hline
\end{tabular}


Table 6. Effect of genotype distribution of studied SNPs for OCT3 gene on glycemic control and on $\mathrm{HbA1c}$ level in Jordanian T2DM patients receiving metformin.

\begin{tabular}{|c|c|c|c|c|c|c|c|c|}
\hline Gene & SNP ID & Genotype & Total & $\begin{array}{l}\text { Adequate } \\
\text { Glycemic } \\
\text { Control }\end{array}$ & $\begin{array}{l}\text { Inadequate } \\
\text { Glycemic } \\
\text { Control }\end{array}$ & $p$-Value * & $\begin{array}{c}\text { Mean HbA1c } \\
\pm \text { SD }\end{array}$ & $p$-Value * \\
\hline \multirow{12}{*}{ ОСТЗ } & & $\mathrm{CC}$ & 3 & 2 & 1 & \multirow{3}{*}{0.167} & $6.90 \pm 1.05$ & \multirow{3}{*}{0.007} \\
\hline & rs12194182 & $\mathrm{CT}$ & 31 & 8 & 23 & & $8.94 \pm 2.33$ & \\
\hline & & $\mathrm{TT}$ & 163 & 67 & 96 & & $7.93 \pm 2.06$ & \\
\hline & \multirow{3}{*}{ rs2292334 } & $\mathrm{CC}$ & 112 & 46 & 66 & \multirow{3}{*}{0.974} & $7.95 \pm 2.11$ & \multirow{3}{*}{0.762} \\
\hline & & $\mathrm{CT}$ & 78 & 30 & 48 & & $8.04 \pm 2.30$ & \\
\hline & & $\mathrm{TT}$ & 19 & 8 & 11 & & $8.15 \pm 1.79$ & \\
\hline & \multirow{3}{*}{ rs2504927 } & AA & 57 & 22 & 35 & \multirow{3}{*}{0.526} & $7.90 \pm 1.68$ & \multirow{3}{*}{0.232} \\
\hline & & GA & 89 & 33 & 56 & & $8.16 \pm 2.39$ & \\
\hline & & GG & 48 & 20 & 28 & & $8.08 \pm 1.93$ & \\
\hline & \multirow{3}{*}{ rs3123634 } & $\mathrm{CC}$ & 77 & 35 & 42 & \multirow{3}{*}{0.495} & $7.62 \pm 1.91$ & \multirow{3}{*}{0.230} \\
\hline & & $\mathrm{CT}$ & 108 & 38 & 70 & & $8.25 \pm 2.03$ & \\
\hline & & TT & 24 & 11 & 13 & & $7.87 \pm 2.38$ & \\
\hline
\end{tabular}

3.3. Correlation of Glycemic Control with Age, BMI, and Age at Diabetes Diagnosis Using Multinomial Logistic Regression

The association of SNP genotype frequencies of the studied polymorphisms with glycemic control was also assessed after adjusting for the following covariates: age, BMI, and age at diabetes diagnosis (Table 7). The multinomial logistic regression analysis showed that SNP genotypes, BMI and age of diagnosis were significantly associated with glycemic control ( $p$-value $<0.05)$. Finally, there was no significant correlation between the studied SNPs and glycemic control after adjustment for age $(p>0.05)$.

Table 7. Associations of SNPs with glycemic control in multinomial logistic regression after adjustment for age, BMI and age at diabetes diagnosis.

\begin{tabular}{ccccc}
\hline Gene & SNP ID & Age $^{*}$ & BMI $^{*}$ & Age at Diabetes Diagnosis \\
\hline & rs1867351 & 0.329 & 0.025 & 0.028 \\
& rs2282143 & 0.268 & 0.017 & 0.027 \\
OCT1 & rs2297374 & 0.323 & 0.021 & 0.033 \\
& rs461473 & 0.352 & 0.019 & 0.043 \\
& rs4646272 & 0.246 & 0.025 & 0.038 \\
& rs622342 & 0.092 & 0.002 & 0.036 \\
& rs683369 & 0.226 & 0.048 & 0.019 \\
\hline \multirow{5}{*}{ OCT2 } & rs10755577 & 0.375 & 0.014 & 0.056 \\
& rs17588242 & 0.332 & 0.021 & 0.035 \\
& rs17589858 & 0.174 & 0.019 & 0.024 \\
& rs2928035 & 0.176 & 0.003 & 0.036 \\
& rs316024 & 0.353 & 0.040 \\
& rs316025 & 0.282 & 0.016 & 0.039 \\
& rs316026 & 0.315 & 0.013 & 0.045 \\
& rs533452 & 0.320 & 0.008 & 0.022 \\
OCT3 & rs662301 & 0.308 & 0.009 & 0.058 \\
& rs12194182 & 0.214 & 0.021 & 0.035 \\
\hline & rs2292334 & 0.243 & 0.013 & 0.035 \\
& rs2504927 & 0.284 & 0.010 & 0.023 \\
\hline
\end{tabular}

${ }^{*} p$-value $<0.05$ is considered significant. 


\section{Discussion}

Recent successes in identifying common variants associated with T2DM elucidated their relationship with the pathophysiology of the disease, which further aids in the evaluation of individual risk and treatment success [22]. Despite an increasingly widespread prevalence in Jordan, T2DM has not been the subject of adequate pharmacogenetic investigation in the Jordanian population. Subsequently, the present study is highly relevant in that it sheds some light on the link between variation in metformin metabolism and Jordanian genetic profiles. This study served to analyze twenty-one confirmed T2DM-predisposing variants in the SLC22A1, SLC22A2, and SLC22A3 genes and the extent of their association with adequate glycemic control. The aforementioned genes are especially pertinent to the field of drug transport because they encode the OCT proteins, which are organic cation transporters that play key roles in the regulation of essential metabolic pathways [23,24].

OCT1, encoded by the SLC22A1 gene, is responsible for the bulk of hepatic metformin uptake [25]. Pharmacogenetic studies on mice revealed that mice with a knockout OCT1 gene exhibited lower hepatic concentrations of metformin in addition to an impaired glucose-lowering effect [26]. Healthy subjects with reduced OCT1 function due to R61C, G4015, 420 del, or G46512 polymorphisms have shown a profound effect on metformin pharmacokinetics, indicating that the OCT1 genotype is a determinant of the latter [27,28]. Another study showed that the rs187351, rs4709400, rs628031, and rs2297374 SNPs affect glycemic outcomes after metformin treatment in Han Chinese T2DM patients [29]. However, a study conducted in the Caucasian population found that only the rs622342 SNP was associated with glycemic outcome [30]. On the contrary, a recent meta-analysis concluded that none of the SLCA22A1 SNPs had any significant effect on glycemic response or HbA1c levels in T2DM patients [31]. The results of the current study show no significant association between glycemic outcomes after metformin treatment and the rs622342 SNP or any of the other studied SLC22A1 SNPs shown in Table 4. This observation indicates that these polymorphisms have no effect on $\mathrm{HbA1c}$ levels in Jordanian T2DM patients taking metformin.

The SLC22A2 gene encodes for the OCT2 protein, which facilitates the transport of metformin from the bloodstream into the renal epithelial cells [30]. Genetic variants in the SCL22A2 gene, such as T199I, T201M, and A270S, have been associated with an increased plasma concentration and a decreased renal clearance of metformin [26]. Recent studies have also found that compounds with a guanidine group like metformin are better substrates for OCT2 in mice and humans [32]. In fact, the OCT2 gene variant $808 \mathrm{G}>\mathrm{T}$ showed a profound effect on metformin pharmacokinetics in healthy subjects by exhibiting an association with higher plasma concentrations [32]. Additionally, the $808 \mathrm{G}<\mathrm{T}$ polymorphism also demonstrated reduced renal metformin clearance in healthy Chinese subjects [33]. However, no significant association between renal metformin clearance and certain SLC22A2 SNPs (rs10755577, rs17588242, rs17589858, rs2928035, rs312024, rs312025, rs312026, rs3127573, rs533452, and rs662301) was detected in healthy Caucasian males [34]. However, the current study did not find any statistical significance to show that any of the studied SLC22A2 SNPs shown in Table 5 to have any effect on glycemic control.

The OCT3 protein, which is coded for by the SLC22A3 gene, is thought to be involved in metformin uptake into hepatocytes and the interstitial fluid [19]. In healthy male Caucasians, no statistically significant association between four SLC22A3 SNPs (rs12194182, rs2292334, rs2504927, and rs3123634) and metformin pharmacokinetics was found [34]. It has also been reported that the rs2292334 SNP is associated with a decreased risk of T2DM and a decrease in HbA1c levels [35]. The current study concluded that the rs12194182 SNP in the SLC22A3 gene is linked to lower mean HbA1c levels in the Jordanian T2DM patients. Subjects with the CC genotype exhibited the lowest mean HbA1c levels, while patients with the $\mathrm{CT}$ and TT genotypes exhibited higher levels. However, the other studied SNPs (rs2292334, rs2504927, and rs3123634) were in accordance with the findings of Tzvetkov et al. [34] as no significant link was established between these SNPs and glycemic control or mean HbA1c levels. These reports, in addition to the results of the present study, show that OCT3 might be somewhat associated with metformin's effect on HbA1c levels. 
Finally, after adjusting for BMI and age at diabetes diagnosis using multinomial logistic regression, this study found a genetic association between glycemic control and all tested SNPs within SLC22A1, SLC22A2 and SLC22A3 genes (Tables 2 and 7). The differences in BMI values between patients or the differences in effect size between different populations might be the reasons why the effect of the aforementioned SNPs could not be replicated in the current study. The variability in age at diabetes diagnosis also has a major effect on the genetic association of these SNPs with glycemic control in the treatment of diabetes. These covariate factors should be considered when treating patients with diabetes. It is also important to clarify the impact of these factors on the genetic associations with glycemic control in the T2DM population.

One potential limitation of the present study is that the duration of the diagnosis was not considered, and subjects who had the disease for a longer time could have decreased production of endogenous insulin, meaning that levels of endogenous insulin among the subjects were variable. Another limitation to be considered is that not all patients were taking the same dosage of metformin, and no baseline levels of $\mathrm{HbA1c}$ were recorded to study the degree in which these levels were affected by metformin monotherapy. Most importantly, the relatively small sample size could limit the ability to extrapolate results to the general population. However, it is important to note that the present study is the first to investigate the association between the aforementioned SLC22A SNPs and TD2M in the Jordanian population.

\section{Conclusions}

The present study revealed that the rs12194182 SNP of the SLC22A3 gene was associated with better HbA1c levels. However, this SNP was not associated with glycemic control after applying the multiple comparison analysis with $p$ value $>0.002$. Owing to the high prevalence of the disease and its complications among the Jordanian population, the results of this study might provide great benefits for patients upon the introduction of personalized T2DM therapy in Jordan. The initiation of early individual-based treatment would aid in disease prognosis and hopefully lead to lower rates of microvascular and macrovascular T2DM complications due to better and more focused treatment regimens.

Author Contributions: Data curation, L.A.-E., A.N. and N.S.; Formal analysis, L.A.-E., B.A. and B.S.; Funding acquisition, L.A.-E.; Investigation, L.A.-E., B.A., A.N. and B.S.; Methodology, L.A.-E., B.A., A.N. and B.S.; Project administration, L.A.-E.; Resources, L.A.-E. and N.S.; Software, L.A.-E. and B.A.; Supervision, L.A.-E. and B.A.; Validation, L.A.-E.; Visualization, L.A.-E. and N.S.; Writing-original draft, L.A.-E., B.A., A.N., B.S. and N.S.; Writing-review and editing, L.A.-E., B.A., A.N., B.S. and N.S.

Funding: This research was funded by the Deanship of Research at Jordan University of Science and Technology, Grant No. 20130242.

Conflicts of Interest: The authors declare no conflict of interest.

\section{References}

1. Tuomi, T.; Santoro, N.; Caprio, S.; Cai, M.; Weng, J.; Groop, L. The many faces of diabetes: A disease with increasing heterogeneity. Lancet 2014, 383, 1084-1094. [CrossRef]

2. Karalliedde, J.; Gnudi, L. Diabetes mellitus, a complex and heterogeneous disease, and the role of insulin resistance as a determinant of diabetic kidney disease. Nephrol. Dial. Transplant. 2014, 31, gfu405. [CrossRef] [PubMed]

3. Wu, Y.; Ding, Y.; Tanaka, Y.; Zhang, W. Risk factors contributing to type 2 diabetes and recent advances in the treatment and prevention. Int. J. Med. Sci. 2014, 11, 1185-1200. [CrossRef]

4. Abuyassin, B.; Laher, I. Diabetes epidemic sweeping the Arab world. World J. Diabetes 2016, 7, $165-174$. [CrossRef] [PubMed]

5. Ajlouni, K.; Khader, Y.S.; Batieha, A.; Ajlouni, H.; El-Khateeb, M. An increase in prevalence of diabetes mellitus in Jordan over 10 years. J. Diabetes Complicat. 2008, 22, 317-324. [CrossRef] [PubMed] 
6. Alghadir, A.; Alghwiri, A.A.; Awad, H.; Anwer, S. Ten-year Diabetes Risk Forecast in the Capital of Jordan: Arab Diabetes Risk Assessment Questionnaire Perspective-A Strobe-Complaint Article. Medicine 2016, 95, e3181. [CrossRef] [PubMed]

7. Kulwicki, A.D.; Kepler, C. Assessment of cardiovascular risk factors among residents of a city in Jordan. J. Cult. Divers. 2001, 8, 34-40.

8. Zindah, M.; Belbeisi, A.; Walke, H.; Mokdad, A.H. Obesity and diabetes in Jordan: Findings from the behavioral risk factor surveillance system, 2004. Prev. Chronic Dis. 2008, 5, A17. [PubMed]

9. Al-Nsour, M.; Zindah, M.; Belbeisi, A.; Hadaddin, R.; Brown, D.W.; Walke, H. Prevalence of selected chronic, noncommunicable disease risk factors in Jordan: Results of the 2007 Jordan Behavioral Risk Factor Surveillance Survey. Prev. Chronic Dis. 2012, 9, E25. [CrossRef]

10. Khader, Y.; Batieha, A.; Ajlouni, H.; El-Khateeb, M.; Ajlouni, K. Obesity in Jordan: Prevalence, associated factors, comorbidities, and change in prevalence over ten years. Metab. Syndr. Relat. Disord. 2008, 6, 113-120. [CrossRef]

11. Triggle, C.R.; Ding, H. Metformin is not just an antihyperglycaemic drug but also has protective effects on the vascular endothelium. Acta Physiol. 2017, 219, 138-151. [CrossRef]

12. Pawlyk, A.C.; Giacomini, K.M.; McKeon, C.; Shuldiner, A.R.; Florez, J.C. Metformin pharmacogenomics: Current status and future directions. Diabetes 2014, 63, 2590-2599. [CrossRef] [PubMed]

13. AL-Eitan, L.N.; Nassar, A.M.; Saadeh, N.A.; Almomani, B.A. Evaluation of Glycemic Control, Lifestyle and Clinical Characteristics in Patients with Type 2 Diabetes Treated at King Abdullah University Hospital in Jordan. Can. J. Diabetes 2016, 40, 496-502. [CrossRef]

14. Florez, J.C. It's Not Black and White: Individualizing Metformin Treatment in Type 2 Diabetes. J. Clin. Endocrinol. MeTable 2014, 99, 3125-3128. [CrossRef]

15. Al-Eitan, L.N.; Nassar, A.M.; Dajani, R.B.; Almomani, B.A.; Saadeh, N.A. Diabetes mellitus in two genetically distinct populations in Jordan. A Comparison between Arabs and Circassians/Chechens Living with Diabetes. Saudi Med. J. 2017, 38, 163-169. [CrossRef] [PubMed]

16. Imam, T.H. Changes in metformin use in chronic kidney disease. Clin. Kidney J. 2017, 10, 301-304. [CrossRef]

17. Wang, L.; Weinshilboum, R. Metformin pharmacogenomics: Biomarkers to mechanisms. Diabetes 2014, 63, 2609-2610. [CrossRef] [PubMed]

18. Hundal, R.S.; Krssak, M.; Dufour, S.; Laurent, D.; Lebon, V.; Chandramouli, V.; Inzucchi, S.E.; Schumann, W.C.; Petersen, K.F.; Landau, B.R.; et al. Mechanism by which metformin reduces glucose production in type 2 diabetes. Diabetes 2000, 49, 2063-2069. [CrossRef]

19. Gong, L.; Goswami, S.; Giacomini, K.M.; Altman, R.B.; Klein, T.E. Metformin pathways: Pharmacokinetics and pharmacodynamics. Pharmacogenet. Genom. 2012, 22, 820-827. [CrossRef]

20. Kimura, N.; Masuda, S.; Tanihara, Y.; Ueo, H.; Okuda, M.; Katsura, T.; Inui, K.-I. Metformin is a superior substrate for renal organic cation transporter OCT2 rather than hepatic OCT1. Drug Metab. Pharmacokinet. 2005, 20, 379-386. [CrossRef]

21. Florez, J.C. The pharmacogenetics of metformin. Diabetologia 2017, 60, 1648-1655. [CrossRef] [PubMed]

22. Lango, H.; Palmer, C.N.A.; Morris, A.D.; Zeggini, E.; Hattersley, A.T.; McCarthy, M.I.; Frayling, T.M.; Weedon, M.N.; Weedon, M.N. Assessing the Combined Impact of 18 Common Genetic Variants of Modest Effect Sizes on Type 2 Diabetes Risk. Diabetes 2008, 57, 3129-3135. [CrossRef]

23. Nigam, S.K. The SLC22 Transporter Family: A Paradigm for the Impact of Drug Transporters on Metabolic Pathways, Signaling, and Disease. Annu. Rev. Pharmacol. Toxicol. 2018, 58, 663-687. [CrossRef]

24. Pochini, L.; Galluccio, M.; Scalise, M.; Console, L.; Indiveri, C. OCTN: A Small Transporter Subfamily with Great Relevance to Human Pathophysiology, Drug Discovery, and Diagnostics. SLAS Discov. Adv. Life Sci. RED 2019, 24, 89-110.

25. Tkáč, I.; Klimčáková, L.; Javorský, M.; Fabianová, M.; Schroner, Z.; Hermanová, H.; Babjaková, E.; Tkáčová, R. Pharmacogenomic association between a variant in SLC47A1 gene and therapeutic response to metformin in type 2 diabetes. Diabetes Obes. MeTable 2013, 15, 189-191. [CrossRef]

26. Becker, M.L.; Visser, L.E.; van Schaik, R.H.N.; Hofman, A.; Uitterlinden, A.G.; Stricker, B.H.C. Genetic Variation in the Multidrug and Toxin Extrusion 1 Transporter Protein Influences the Glucose-Lowering Effect of Metformin in Patients with Diabetes: A Preliminary Study. Diabetes 2009, 58, 745-749. [CrossRef] [PubMed] 
27. Shu, Y.; Brown, C.; Castro, R.; Shi, R.; Lin, E.; Owen, R.; Sheardown, S.; Yue, L.; Burchard, E.; Brett, C.; et al. Effect of Genetic Variation in the Organic Cation Transporter 1, OCT1, on Metformin Pharmacokinetics. Clin. Pharmacol. Ther. 2008, 83, 273-280. [CrossRef] [PubMed]

28. Hosseyni-Talei, S.R.; Mahrooz, A.; Hashemi-Soteh, M.B.; Ghaffari-Cherati, M.; Alizadeh, A. Association between the synonymous variant organic cation transporter 3 (OCT3)-1233G $>A$ and the glycemic response following metformin therapy in patients with type 2 diabetes. Iran. J. Basic Med. Sci. 2017, 20, 250-255.

29. Zhou, Y.; Ye, W.; Wang, Y.; Jiang, Z.; Meng, X.; Xiao, Q.; Zhao, Q.; Yan, J. Genetic variants of OCT1 influence glycemic response to metformin in Han Chinese patients with type-2 diabetes mellitus in Shanghai. Int. J. Clin. Exp. Pathol. 2015, 8, 9533-9542. [PubMed]

30. Becker, M.L.; Visser, L.E.; van Schaik, R.H.N.; Hofman, A.; Uitterlinden, A.G.; Stricker, B.H.C. Genetic variation in the organic cation transporter 1 is associated with metformin response in patients with diabetes mellitus. Pharmacogenom. J. 2009, 9, 242-247. [CrossRef] [PubMed]

31. Dujic, T.; Zhou, K.; Yee, S.; van Leeuwen, N.; de Keyser, C.; Javorský, M.; Goswami, S.; Zaharenko, L.; Hougaard Christensen, M.; Out, M.; et al. Variants in Pharmacokinetic Transporters and Glycemic Response to Metformin: A Metgen Meta-Analysis. Clin. Pharmacol. Ther. 2017, 101, 763-772. [CrossRef] [PubMed]

32. Song, I.; Shin, H.; Shim, E.; Jung, I.; Kim, W.; Shon, J.; Shin, J. Genetic Variants of the Organic Cation Transporter 2 Influence the Disposition of Metformin. Clin. Pharmacol. Ther. 2008, 84, 559-562. [CrossRef] [PubMed]

33. Wang, Z.-J.; Yin, O.Q.P.; Tomlinson, B.; Chow, M.S.S. OCT2 polymorphisms and in-vivo renal functional consequence: Studies with metformin and cimetidine. Pharmacogenet. Genom. 2008, 18, 637-645. [CrossRef]

34. Tzvetkov, M.V.; Vormfelde, S.V.; Balen, D.; Meineke, I.; Schmidt, T.; Sehrt, D.; Sabolić, I.; Koepsell, H.; Brockmöller, J. The Effects of Genetic Polymorphisms in the Organic Cation Transporters OCT1, OCT2, and OCT3 on the Renal Clearance of Metformin. Clin. Pharmacol. Ther. 2009, 86, 299-306. [CrossRef]

35. Mahrooz, A.; Alizadeh, A.; Hashemi-Soteh, M.B.; Ghaffari-Cherati, M.; Hosseyni-Talei, S.R. The Polymorphic Variants rs3088442 and rs2292334 in the Organic Cation Transporter 3 (OCT3) Gene and Susceptibility Against Type 2 Diabetes: Role of their Interaction. Arch. Med. Res. 2017, 48, 162-168. [CrossRef] [PubMed]

(C) 2019 by the authors. Licensee MDPI, Basel, Switzerland. This article is an open access article distributed under the terms and conditions of the Creative Commons Attribution (CC BY) license (http:/ / creativecommons.org/licenses/by/4.0/). 